\title{
Value Addition to Waste for Sustainable Development
}

\author{
Raji S. ${ }^{1}$, D.D.Sarode ${ }^{2}$ \\ ${ }^{1,2}$ Department of General Engineering, Institute of Chemical Technology, Matunga, Mumbai, 400019, India
}

\begin{abstract}
The effect on environment by agricultural and other industrial wastes is increasing and causing a lot of problems. It is estimated that about 500 million tons of agricultural and agro-industrial residues are being generated annually in the country. Adequate means of disposing these wastes are lacking, hence, converting them to value added products such as briquettes for domestic as well as industrial fuel is desirable. This study aims to establish a mix of options for organic waste processing that can deliver better economic and environmental outcomes than the production of low quality compost or other means that have limited market potential. The present review aims at summarizing value addition options for various biomasses towards energy production and value added product generation.
\end{abstract}

Keywords: waste; biomass; bioenergy; briquettes; sustainable development

\section{Introduction}

India produces nearly 500 million tons of agricultural waste per year. It has been estimated that 120-150 million tons crop residues is surplus to its present utilization as a cattle feed, constructional and industrial raw material and as industrial fuel[1].About $46 \%$ of the total energy consumption is estimated to be met from various biomass residues viz., agriculture residues, animal dung, forest waste, fire wood etc. [2]. The major portion of the agriculture residues produced in the country is used for domestic utility [3]. The direct burning of agriculture residues in domestic as well as industrial application is very inefficient due to wide range of biomass sizes and varying water content coupled with more ash content. Moreover transportation, storage, handling and other logistic issues also create problems in their sustainable utilization. The forest/agricultural biomass based briquette production technology has significant utility and made tremendous impact in terms of value addition of underutilized biomass. Conversion of biomass into value added briquettes help to create adequate socio economic and environmental impact. The study reveals that the establishment of decentralized value addition units may result in efficient utilization of biomass residues. The conversion of various types of locally available biomass into briquettes will result in meeting the energy requirements of the country with reduced impact on environment [4].There are incentives for the promotion of waste to energy by Ministry of New and Renewable Energy and Indian Renewable Energy Development Agency (IREDA).These incentives are in the form of rebate in capital subsidy, central excise duty, income tax and loan interest rate etc.

\section{Methodology}

The method adopted for this study involved extensive literature review on the subject matter. Sources used included internet, previous reports of ministry of environment, Government agencies and publications of notable researchers on biomass, particularly on biomass briquetting. The present review aims at summarizing value addition options for various biomass wastes towards energy production and value added product generation.

\section{Briquetting}

Briquetting is the process of compaction of residues commonly known as densification which converts biomass into a product of higher density than the original raw materials. [5]. Due to densification handling characteristics of material for packaging, transportation and storage are also improved[6].Briquettes produced from locally available biomass are low in cost and easily available to consumers, for domestic cooking and agro-industrial operations. This serve as compliments to fire wood and charcoal thereby reducing the high demand for both [7].Besides, briquettes have advantages over fire wood in terms of greater heat intensity, cleanliness, convenience in use and relatively smaller space requirement for storage [5]. The briquettes are normally cylindrical or rectangular in shape [8].

\subsection{Need for Briquetting}

Biomass for fuel usually has low economic value such as bagasse, corn cob, coffee husk, coconut shell, palm oil shell, saw-dust and cocoa pod [9]. Direct biomass burning without processing will cause respiratory problem because of its carbon monoxide, sulphur dioxide (SO2) and particulate material [10]. Bergman and Zerbe [11] found that biomass densification to a better form can increase its quality and efficiency as fuel. A positive energy balance should be considered, so that the energy content should be higher than the energy for the production process [12]. In order to achieve more efficient usage of agro residues, it is essential to densify them to compact pieces of definite size and shape with high thermal value. The briquetting of biomass improves its handling characteristics, increases the calorific value, reduces transportation costs and makes it available for a variety of application. The biomass briquette is a fuel consisting of biomass, such as agricultural waste or waste paper, bound together and compressed into small pieces approximately 5 to $15 \mathrm{~cm}$. Briquette-making can serve as cottage industry in areas where these bio-wastes are in abundance [13].

\subsection{Applications of Briquettes}


Briquettes have many numerous uses which include both domestic and small industrial cottage applications [14].

- Cooking and water heating in households;

- Heating productive processes such as tobacco curing, fruits, tea drying, poultry rearing etc

- Firing ceramics and clay wares such as improved cook stoves, pottery, bricks etc;

- Fuel for Gasifiers to generate electricity;

- Powering boilers to generate steam.

\subsection{Advantages of Briquettes}

- Biomass briquettes offer many benefits over traditional fuels like coal, fuel oil, natural gas and propane as well as over the pre-compacted raw materials like wood chips, paper, green wood etc.

- The purchase price of biomass briquettes is less than natural gas, propane and fuel oil. Compacting biomass waste into briquettes reduces the volume by ten times, making it much easier to store and transport. They have a long shelflife.

- Briquettes are immeasurably cleaner than the other fuel alternatives used in rural and industrial applications.

- Briquettes burn in a controlled manner, slow and efficiently [15].

- Product has consistent quality, burning efficiency also ideally sized for complete combustion.

- It helps to reduce the scientific disposal of the waste.

- Generates rural employment and as a source of supplementary income.

\section{Briquetting Process}

The major steps generally involved in the briquetting process are:

\subsection{Collection of raw materials and its processing}

In general, any material that will burn, but is not in a convenient shape, size or form, to be readily usable as fuel is a good raw material for briquetting. The preparation of raw materials includes drying, size reduction, mixing of raw materials in correct proportion, mixing of raw materials with binder etc.The raw materials available having higher moisture content than what required for briquetting, can be dried in open air (sun), in solar driers, with a heater or with hot air.The raw material is first reduced in size by shredding, chopping, crushing, breaking, rolling, hammering, milling, grinding, cutting etc. until it reaches a suitably small and uniform size (1 to $10 \mathrm{~mm}$ ). For some materials such as sawdust which are available in the size range of 1 to $10 \mathrm{~mm}$ need not be size reduced. Since the size reduction process consumes a good deal of energy, this should be as less as possible.

\subsection{Preparation of briquettes}

It is desirable to make briquettes of more than one raw material. Mixing will be done in proper proportion in such a way that the product should have good compaction and high calorific value with minimum energy input. Compaction process takes place inside the briquetting machine. The process depends on the briquetting technology adopted.

Once the Briquettes are ready, the calorific value, analysis of gas emitted and ash produced need to be tested.

\section{Raw Materials for Briquetting}

Biomass briquettes are made by compressing loose biomass residues or waste, to produce compact solid blocks of different sizes and shapes. They are made by applying pressure, heat and use of binding agent to combine the loose materials to produce briquettes of different shapes and sizes. Review reveals that almost all type of Agro-Forest waste can be used as biomass, including Wood chips, Wood shavings, Saw dust, Wheat straw, Rice husk, Sunflower husk, Groundnut shell, Sugar cane bagasse, Tamarind pod, Maize stalk, Corncob, Palm fruit bunch, Cotton Stalks, Coffee Husk, Paddy Straw, Tobacco waste, Mustard Stalk, Jute waste, Bamboo Dust, Tea waste, Soybeans husk, dried tapioca stick, Coconut and Palm root, frond, shell, husk, Banana plant waste and roots, Forestry wastes and many other Agro wastes.

Literature review reveals that all these raw materials can be briquetted individually and in combination with or without using binders. The factors that mainly influence on the selection of raw materials are moisture content, ash content, flow characteristics, particle size and availability in the locality. Moisture content in the range of $120-15 \%$ is preferred because high moisture content will pose problems in grinding and more energy is required for drying [16]. The ash content of biomass affects its slagging behavior together with the operating conditions and mineral composition of ash. Biomass feedstock having up to $4 \%$ of ash content is preferred for briquetting. The granular homogeneous materials which can be handled by conveyers, bunkers and storage silos are suitable for briquetting.

A study on briquetting was carried out with olive refuse and paper mill waste was conducted to form fuel briquettes [17]. Richards S.R. [18] considered four physical properties that are of greatest value when developing or evaluating efficient fuel briquette formulations or processes. They are resistances to crushing, impact, abrasion and water penetration. Blesa M. J et al[19]. Lucy Wamukonya et al.[20] studied about densification of agricultural residues and wood waste into fuel briquettes that can provide a relatively high-quality alternative source of fuel, especially where solid wood fuel resources are scarce. Oladeji J.T[21] have carried out their studies on a physical and fuel Characteristics of Rice Husk and Corncob Briquettes, Suparin Chaiklangmuang et al. [22] studied briquetting of lignite combined with biomass binders. Chin Yee Sing et al. [23] presented a systematic approach in utilizing the large amount of palm oil mill residues that are loosely-bounded and have low energy density. With value addition such as briquetting through carbonization or semi decomposition, higher energy yielding briquettes can be obtained. [24].The preparation and characterization of solid biomass fuel made from rice straw and rice bran were studied[25]. Yumak et al.[26] produced briquettes from soda weed (Salsolatragus) to be used as a rural fuel source. The production of bio briquettes from carbonized brown seaweed 
was evaluated [27] and the effects of briquetting pressure on banana-peel briquettes and on banana waste in northern Thailand by Weapon [28]. The study reveal that the pseudo stem briquettes showed higher compressive strength compared with leaves banana briquettes. The pseudo stem showed a more fibrous structure, and according to Furtado et al. [29] higher the proportion of fibre in the entire material the greater will be its resistance to compression. Zannikos F.et al. [30] examined the production of briquettes for household use from biomass in combination with plastic materials from different sources. The combustion characteristics of the briquettes in a common open place were also studied. The smoke levels were between the 3rd and 4th grades of the smoke number scale. Measuring the carbon monoxide emission, it was observed that the burning of the plastic in the mixture with biomass increases the carbon monoxide emissions from $10 \%$ to $30 \%$ as compared to carbon monoxide emission from sawdust biomass emissions (without plastic) which was used as a reference. Review reveals that bio waste from tender coconut collected from streets were processed and turns them into combustible briquettes. [31]

\subsection{Factors affecting Biomass briquetting}

Particle Size: Particle size and shape are of great importance for densification. It is generally agreed that biomass material of $6-8 \mathrm{~mm}$ size with $10-20 \%$ powdery component gives the best results [5].

Moisture: Studies found that when the feed moisture content is $10-12 \%$, the briquettes will have $8-10 \%$ moisture [16]. At this moisture content, the briquettes are strong and free of cracks and the briquetting process is smooth. However, when the moisture content is more than $15 \%$, the briquettes are poor and weak and the briquetting operation is erratic $[5]$.

Temperature: By varying the temperature of biomass, the briquette density, briquette crushing strength and moisture stability can be varied [32].

Additives: The briquetting process does not add to the calorific value of the base biomass. In order to upgrade the specific heating value and combustibility of the briquette, certain additives like waste plastic, oil waste, charcoal and coal in very fine form can be added[33].

\subsection{Characteristics of biomass}

The literature identified some important biomass fuel properties that have an influence on the combustion: in particular moisture content, fuel volatile content, ash content and calorific value. The effect on the combustion of each of these properties was studied [34].The proximate analysis is a standardized analysis procedure [35] that attempts to quantify some key physical characteristics of biomass, which affect its combustion characteristics. This is done by considering biomass to be made up of four main components: moisture content, volatile matter, ash content and fixed carbon.

Ultimate Analysis involves the estimation of important chemical elements that make up the biomass, namely car- bon, hydrogen, oxygen, nitrogen and sulphur. The calorific value (or heating value) is the standard measure of the energy content of a fuel [36].It is the property that depends on its chemical composition and moisture content. The calorific value is the most important fuel property [37].

In order to improve the mechanical strength of the biobriquettes, some additives and binding materials are added to biomass and they are briquetted together in the same briquetting mould. For this purpose, various additives such as humates, molasses, H3PO4, and sulphite liquor have been used in briquetting. The exothermic reaction of some binders such as molasses and lime during briquetting provides the removal of the moisture in the briquette [38].

\section{Briquetting Technology}

Different technologies that are being used for manufacturing of briquettes are reviewed. On the basis of compaction, the briquetting technologies can be divided into: High pressure compaction, medium pressure compaction with a heating device and low pressure compaction with a binder $[16,7]$. There are two high-pressure technologies: Piston press and screw extrusion machines used for briquetting. The briquettes produced by a piston press are completely solid, while screw press briquettes have a concentric hole, which gives better combustion characteristics due to a larger specific area. The screw press briquettes are also homogenous and do not disintegrate easily. Having a high combustion rate, they can substitute for coal in most industrial applications and in boilers. Briquettes can be produced with a density of $1200 \mathrm{Kg} / \mathrm{m} 3$ from loose biomass of bulk density 100 to $200 \mathrm{Kg} / \mathrm{m} 3$. A higher density gives the briquette a higher heat value $(\mathrm{KJ} / \mathrm{Kg})$, and makes the briquettes burn more slowly as compared to the raw materials from which the briquettes are made [5].Anita Shrestha et al. [39] presented an experimental production of solid waste briquettes from municipal solid waste mainly plastic and paper by screw extrusion technology and piston press technology. Ramesh Man Singh et al. [40] prepared composite fuel Bio-briquettes from a mixture of biomass and coal in a roller press briquetting machine. A.O. Inegbenebor [41] have carried out studies on fibrous agricultural and wood waste materials that have been compressed with suitable adhesive into solid fuel briquettes in a compressing machine, which was designed and constructed for this purpose. Olawole Abiola Kuti [42] produced composite sawdust briquette fuel and utilized in order to simulate cooking.

Screw extrusion [16] briquetting machines are popular densification equipment suitable for small-scale application in developing countries. In screw presses, material is fed continuously into a screw, which forces the material into a cylindrical die. This die is often heated to raise the temperature to the point where lignin flow occurs. If the die is not heated, then the temperature may not rise sufficiently to cause lignin flow and binding materials may have to be added [43].These can be molasses, starch, or some cheap organic materials. The briquettes from screw machines are often of higher quality than from piston units. The screw press is usually sized in the range $75-250 \mathrm{~kg} / \mathrm{h}$, though, larger machines are available. The screw press can produce denser and stronger briquettes than those produced by piston presses [44]. There

\section{Volume 8 Issue 2, February 2019 www.ijsr.net}


are basically three types of screw press. These are: Conical screw press, screw press with heated dies, and screw press without heated dies [16].

The piston press is one of the main high press technologies used for briquetting. The piston press acts in a discontinuous mode with material being fed into a cylinder, which is compressed by a piston into a slightly tapering die [45]. The compressed material is heated by frictional forces as it is pushed through the die. The lignin contained in all woody cellulose materials begins to flow and acts as a natural glue to bind the compressed material. When the material emerges from the die, the lignin solidifies and holds it together, forming cylindrical briquettes which readily break into pieces about $10-30 \mathrm{~cm}$ long. The briquettes produced by a piston press are completely solid. The production rate of these machines is between $25-1800 \mathrm{~kg} / \mathrm{h}$, depending on the press canal diameter, the kind of materials pressed, and their properties. Basically, there are two types of piston press. These are the mechanical and hydraulic piston presses [16].Mechanical piston presses generally produce hard and dense briquettes from most materials [16]. Hydraulic piston press can possibly be considered when looking for a small briquetting machine, which makes briquettes, which are less dense and are sometimes soft and friable.

Pellets are the results of a process, which is closely related to the briquetting processes. The main difference is that the dies have smaller diameters (usually up to approximate 30 $\mathrm{mm}$ ) and each machine has a number of dies arranged as holes bored in a thick steel disc ring [46]. The material is forced into the dies by means of rollers (normally two or three) moving over the surface on which the raw material is distributed. The pressure is built up by the compression of this layer of material as the roller moves perpendicular to the center line of the dies [47]. The main application of pellet machines is to produce animal feed from various types of agricultural wastes. Only a very limited number of plants have been set up to produce fuel pellets [48]. The most standard pellets machines are roller presses with a circular die and cogwheel pellet principle. Such machines were originally developed for the production of animal feeds. These operate by extruding small pellets of diameter $10-30 \mathrm{~mm}$ through a die that has many holes. The extruding mechanism is often an eccentric roller that moves inside the large cylindrical or conical die. Its performance depends on various parameters; the most important of these is the fineness of the pressed materials [49]. Pellets can be used in automatically charged stoves for domestic cooking and in boilers due to their good flow ability, uniform water content, grain size and chemical composition.

\section{Conclusion}

Waste-to-energy conversion technologies not only extend the life of landfill but also provide an alternative energy resource by utilizing unused waste products. Locally available agriculture/forest waste in combination with other easily available waste materials such as paper, wood chips, oil waste etc. can be used to produce value added pellets or briquettes. The process adopted and type of equipment to be used for conversion depends on raw material used, its properties, and volume to be processed and end applications.
In order to reduce the load on landfills, some waste materials dumped into landfills can be converted into value added products. To make the entire process economical and commercially viable, proper selection of material, processing technique and equipment should be adopted so as to produce the end product with good calorific value, less emissions and residue after combustion. To reduce greenhouse gases as well as to overcome the shortage of space for dumping grounds, scientific waste disposal and production of value added products for industrial applications should be encouraged. This will not only enhance the employment opportunity in rural areas but also will be a good source of supplementary income to farmers. The ash produced in local industrial units can be used as manure in agriculture fields. Such activity will also save the fossil fuels required for transportation of these waste materials to dump sites.

\section{References}

[1] Ministry of New and Renewable Energy in association with Indian Institute of Science, Bangalore www.mnre.gov.in

[2] Ravindranth, N.H. and Hall, D.O. 1995. Biomass Energy and Environment. Oxford University, Press, Oxford.

[3] Tripathi K.Arun,. Iyer, P.V.R and Tara Chandra Kandpal., 1998.A Techno-Economic Evaluation of Biomass Briquetting in India”. Biomass and Bioenergy (14):pp. 479-488

[4] Umesh Kanna, S., Pathiban, K.T., Sekar, I., Vidhayavathi, A., Devanand, P.S., Anbu, P.V and Durairasu, P., 2011. Value addition of agroforestry plantation residues through briquetting technology for energy purpose. Forest College and Research Institute, Tamil Nadu Agricultural University, Mettupalayam - 641 301, India; Short Rotation Forestry and Agroforestry: an Exchange of Experience between CDM Countries and Europe. June 20 - 22, 2011 Marchesi di Barolo, Barolo, Italy Published by the Benwood project consortium, conference proceedings.

[5] Kaliyan, N. and Morey, R. V., 2009. Factors affecting strength and durability of densified biomass products. Biomass and Bio-energy 33, 337-359

[6] Stout, B. A., and Best, G., (2001), "Effective energy use and climate change: needs of rural areas in developing countries", Agricultural Engineering International: the CIGR E-journal of Scientific Research and Development Vol.III 19pp.

[7] Wilaipon P., 2009. The effects of briquetting pressure on banana-peel briquette and the banana waste in northern Thailand. American Journal of Applied Sciences 6, 167-171

[8] Garriot, G., (2004), Agricultural Report-Briquetting Available at http://www.Vitiorgy/

[9] El Bassam, N., dan, P. and Maegaard. 2004. Integrated Renewable Energy or Rural Communities. Planning guidelines, Technologies and Applications. Elsevier, Amsterdam.

[10] Yamada, K., M. Kanada, Q., Wang, K., Sakamoto, I., Uchiyama, T., Mizoguchi dan Y. Zhou. 2005. Utility of Coal-Biomass Briquette for Remediation of Indoor Air 


\section{International Journal of Science and Research (IJSR) \\ ISSN: 2319-7064}

Impact Factor (2018): 7.426

Pollution Caused by Coal Burning in Rural Area, in China. Proceedings: Indoor Air 2005-3671

[11]Bergman, R., Zerbe. Dan J. 2004. Primer on Wood Biomass for Energy. USDA Forest Service, State and Private Forestry Technology Marketing Unit Forest Products Laboratory. Madison, Wisconsin.

[12] Hill, J., Nelson, E., Tilman, D., Polasky, S., and Tiffany, D. 2006. Environmental, economic, and energetic costs and benefits of biodiesel and ethanol biofuels. Proc. Nat. Acad. Sci., 103, 11 206-11 210

[13] Ilavsky, J., and Oravec, M., (2000), "Utilization of Biomass in Slovakia" Ecological Engineering, 16:S83 S89

[14] Ahmed, S., Rahman, M. M., Islam, M.M., Mashud, M., Nawsher, M., and Ali, M. (2008), "Moral Role of Biomass Briquetting in the Renewable Energy Sector and Poverty Diminution for Bangladesh" Proceedings of the 4th BSME-ASME International Conference on Thermal Engineering 27-29 December, 2008, Dhaka,Bangladesh

[15] Sunomi, IIc. High Productivity Solutions for the North American Renewable Energy Market, Benefits of Biomass Briquettes; www.sunomillc. com/benefits

[16] Grover, P.D., and Mishra, S. K., 1996. Biomass Briquetting, Technology and Practices, Regional Wood Energy Development Programme in Asia, Field document No. 46 Bangkok, Thailand; FAO.

[17] Yaman, S., Sahan, M., H Haykiri-axca, K Sesen, S Kukbcuayrak, 2000,"Production of fuel briquettes from olive refuse and paper mill waste"l, Fuel Processing Technology, Volume 68, Issue 1, 23-31.

[18] Richards, S.R., 1990. Physical testing of fuel briquettes. Fuel Processing Volume 25, Issue 2, 89-100

[19]Blesa, M.J., Miranda, J.L., Izquierdo, M.T and Moliner, R. 2003.Curing temperature effect on smokeless fuel briquettes prepared with molasses and H3PO4. www.fuelfirst.com. Volume 82, Issue 13, 1669-1673.

[20]Lucy Wamukonya. and Bryan Jenkins., 1995. Durability and relaxation of sawdust and wheat straw briquettes as possible. Fuels, Volume 8,175-179

[21] Oladeji, J.T., 2010. Briquettes Produced from Corncob and Rice Husk Resides, The Pacific Journal of Science and Technology, Volume 11, 101-106

[22] Suparin Chaiklangmuang, Suwit Supa and Prattana Kaewpet, 2008. Development of Fuel Briquettes from Biomass-Lignite Blends. Journal of science faculty of Chiang Mai University, Vol.35 No.1,43-50

[23] Chin Yee Sing and Shiraz Aris, M. 2013. A Study of Biomass Fuel Briquettes from Oil Palm Mill Residue. Asian Journal of Scientific Research, volume 6, 537545.

[24]El Shinawi, M. M., Alaa El Din, M.N., Shimi, E., and Badawi, M. A. 1989. Biogas production from Crop Residues and Aquatic Weeds. Res Conser Recycle 3: 3345.

[25] Chou C.S., Lin S.H., Lu W.C., 2009. Preparation and characterization of solid biomass fuel made from rice straw and rice bran, Fuel Processing Technology, 90, 980-987

[26] Yumak H., Ucar T., Seyidbekiroglu, N., 2010 Briquetting soda weed (Salsola tragus) to be used as a rural fuel source. Biomass and Bioenergy 34, 630-636
[27] Acma, H.H., Yaman, S. and Kucukbayrak, S. 2013. Production of bio briquettes from carbonized brown seaweed. Fuel Processing Technology 106, 33-40.

[28] Wilaipon, P., (2009), "Density Equation of Bio-Coal Briquettes and Quantity of Maize cob in Phitsanulok, Thailand" American Journal of Applied Sciences 5 (12):1808-1811.

[29] Furtado T.S.,Valin M., Brand M. A., Bellote A.F.J., 2010. Briquetting process variables and quality of forest biomass briquettes. Brazilian Forestry Research 30, 101-106.

[30]Zannikos, F., Kalligeros, S., Anastopoulos, G and E.Lois. 2013. Converting Biomass and Waste Plastic to Solid Fuel Briquettes. Journal of Renewable Energy, Article ID 360368, 9 pages

[31] biofueluptodate.com/waste-coconut-shells/

[32] Joseph, S., and Histop, D., 1999. Residue briquetting in developing countries Energy from Biomass. 3 Elsevier, London, pp.1064-1068

[33] Oladeji, J.T., 2015. Theoretical Aspects of Biomass Briquetting: A Review Study Journal of Energy Technologies and Policy, Vol.5, No.3, 2015

[34] Jekayinfa, S. and Omisakin, O., 2005. The energy potentials of some agricultural wastes as local fuel in Nigeria. Agricultural Engineering International: the CIGR E journal, vol. 7

[35] British Standards Institution, Solid biomass fuelsdetermination of total content of carbon, hydrogen and nitrogen- instrumental methods." draft biomass standard, DD CEN/TS 15104, 2005.

[36] British Standards Institution, Solid biofuels- terminology, definitions and descriptions. Draft biomass standard, DD CEN/TS 14588, 2004.

[37] Aina, O.M., Adetogun, A.C. and Iyiola, K.A. 2009. Heat Energy from Value-Added Sawdust Briquettes of Albizia Zygia Ethiopian.United States Agency International Development.

[38] Haykiri H.-Acma, and Yaman, S. Proceedings of the World Congress on Engineering and Computer Science.2010. Vol II WCECS 2010, October 20-22, 2010, San Francisco, USA.

[39] Anita Shrestha, Ramesh M Singh, 2011. Energy Recovery from Municipal Solid Waste by Briquetting Process: Evaluation of Physical and Combustion Properties of the Fuell. Nepal Journal of Science and Technology, vol.12, 238-241.

[40] Ramesh Man Singh,. Hee Joon Kim,. Mitsushi Kamide,. Toran Sharma,. 2009. Bio briquettes-an Alternative Fuel for Sustainable Development. Nepal Journal of Science and Technology, Vol. 10,121-127

[41] Inegbenebor, A.O., 2002. Production of Solid Fuel Briquettes from Agricultural and Wood Waste (Saw Dust and Rice Husk). African Journal of Science and Technology, Vol 3, No.2.

[42] Olawole Abiola Kuti, 2003. Evaluation of Composite Sawdust Briquette As A High Grade Fuel For Domestic Cooking. Federal University of Technology Akure.

[43] Tabil, L. G., 1997. Binding and Pelleting characteristics of alfalfa. An Unpublished Ph.D dissertation. Saskatoon, Saskatchewan, Canada:- University of Saskatchewan, Department of Agricultural and Bio-resources Engineering 
[44] Singh, R.N., Bhoi, P.R. and Patel, S.R,. 2007. Modification of commercial briquetting machine to produce $35 \mathrm{~mm}$ diameter briquettes suitable for gasification and combustion. Renewable Energy, Vol. 32 No. 3 pp. 474479

[45] Mishra, S.K., 1996. Hard facing of screw for wear resistance. Proceedings of the international workshop on Biomass Briquetting, New Delhi, 3- 6 April 1996

[46] Klass, D.L., 1998. Biomass for renewable energy, fuels, and chemicals. San Diego, Academic Press.

[47] Tumuluru, J.S., Wright, C.T., Kenny, K.L. and Hess, J.R., 2010. A Review on Biomass Densification Technologies for Energy Application. Available at www.inl.aov.

[48] Gilbert, P., Ryu, C., Sharif, V., and Switchenbank, J., 2009. Effect of processing parameters on palletisation of herbaceous crops. Fuel $88: 1491-1497$

[49] Claus, B., 2002.Contribution to the compacting of unchopped crop stalks for energetic use. An Unpublished Ph.D. Thesis TU Chemnitz 